\title{
Self-Renewal Signalling in Presenescent Tetraploid IMR90 Cells
}

\author{
Anda Huna, ${ }^{1}$ Kristine Salmina, ${ }^{1}$ Elina Jascenko, ${ }^{2}$ Gunars Duburs, ${ }^{2}$ \\ Inna Inashkina, ${ }^{1}$ and Jekaterina Erenpreisa ${ }^{1}$
}

${ }^{1}$ Latvian Biomedical Research and Study Centre, Ratsupites 1, 1067 Riga, Latvia

${ }^{2}$ Latvian Institute of Organic Synthesis, Aizkraukles 21, 1006 Riga, Latvia

Correspondence should be addressed to Jekaterina Erenpreisa, katrina@biomed.lu.lv

Received 15 December 2010; Revised 22 February 2011; Accepted 25 February 2011

Academic Editor: Noam Shomron

Copyright () 2011 Anda Huna et al. This is an open access article distributed under the Creative Commons Attribution License, which permits unrestricted use, distribution, and reproduction in any medium, provided the original work is properly cited.

\begin{abstract}
Endopolyploidy and genomic instability are shared features of both stress-induced cellular senescence and malignant growth. Here, we examined these facets in the widely used normal human fibroblast model of senescence, IMR90. At the presenescence stage, a small (2-7\%) proportion of cells overcome the $4 \mathrm{n}-\mathrm{G} 1$ checkpoint, simultaneously inducing self-renewal (NANOG-positivity), the DNA damage response (DDR; $\gamma$-H2AX-positive foci), and senescence (p16inka4a- and p21CIP1-positivity) signalling, some cells reach octoploid DNA content and divide. All of these markers initially appear and partially colocalise in the perinucleolar compartment. Further, with development of senescence and accumulation of p16inka4a and p21CIP1, NANOG is downregulated in most cells. The cells increasingly arrest in the $4 \mathrm{n}-\mathrm{G} 1$ fraction, completely halt divisions and ultimately degenerate. A positive link between DDR, self-renewal, and senescence signalling is initiated in the cells overcoming the tetraploidy barrier, indicating that cellular and molecular context of induced tetraploidy during this period of presenescence is favourable for carcinogenesis.
\end{abstract}

\section{Introduction}

Cellular senescence is a condition in which the cells remain alive but are unable to proliferate. Premature senescence can be triggered by certain stresses independently of the number of cell divisions or telomere length [1], possibly as a result of protracted DNA damage signalling [2]. Oncogene-induced senescence is thought to behave similarly, driven at the very early stages of tumour development where it serves as a barrier to cancer progression [3]. Subsequent progression to full-blown malignancy is favoured when tumour stem cells acquire further mutations that impair the senescence pathway, for example, mutations in TP53 or CDKN2a $[4,5]$.

During in vitro culture, human fibroblast cells undergo a presenescence phenomenon whereby they display evidence of chromosome instability (CIN) within an apparently highly heterogenous population with signs of chromosomal damage, and the appearance of polyploid interphase cells and their divisions [4, 6-12]. Whereas the frequency of diploid mitotic cells at presenescence is declining, the number of polyploid mitoses increases to a peak before a sharp fall as the cells change to the characteristic flat morphology indicative of replicative senescence $[13,14]$. These data stimulated the hypothesis that telomeric loss at senescence may represent a "genetic time bomb" causally involved in both cell senescence and malignant transformation $[13,15]$.

In is clear that CIN associated with polyploidy at the presenescence stage may substantially increase the mutability and risk of malignant transformation [16-18]. Moreover, there are reports from normal cell cultures of revertant cells escaping senescence by acquiring mutations [19] and their ability to depolyploidise and restart mitoses [9-12, 17]. The features of CIN, including polyploidy, are also characteristic of malignant tumors where the degree of CIN is correlated with aggression [20]. Induced endopolyploidy is a typical response of tumour cells with deficient p53 function to the action of DNA or spindle-damaging agents [21-24]. For a decade, it has been generally accepted that sublethal genotoxic damage to cancer cells associated with anticancer clinical modalities accelerates cellular senescence $[1,25]$, with concomitant induction of polyploidy as a component.

However, we and others have recently shown that the induction of endopolyploidy followed by arrest and subsequent slippage from a spindle checkpoint is accompanied 
TABLE 1: Antibodies: source and use.

\begin{tabular}{ll}
\hline Primary antibodies & $\begin{array}{l}\text { Secondary antibodies } \\
\text { (dilution, if not stated otherwise, 1:400) }\end{array}$ \\
\hline Mouse monoclonal anti-hNANOG (N3038, Sigma) $1: 75$ & $\begin{array}{l}\text { Goat anti-mouse IgG-Alexa Fluor 488 (A31619, Invitrogen) or } \\
594 \text { (A31623, Invitrogen) }\end{array}$ \\
$\begin{array}{l}\text { Rabbit polyclonal anti-hOCT4 (ab19857, Abcam) } 1: 200 \\
\text { Goat polyclonal anti-hOCT3/4 (N-20) (sc-8630X, Santa Cruz) } 1: 400\end{array}$ & $\begin{array}{l}\text { Rabbit anti-goat IgG-Cy3 (C2821, Sigma) } 1: 500 \\
\text { Rabbit polyclonal anti-hP21 C-19 (sc-397, Santa Cruz) IF 1:50 }\end{array}$ \\
$\begin{array}{l}\text { Gabbit polyclonal anti-hP16 N-20 (sc-467, Santa Cruz) IF 1:50 } 1: \text { rabbit-IgG- .Alexa Fluor 594 (A31631, Invitrogen) } \\
\text { Mouse monoclonal anti-hPML (sc-966, Santa Cruz) } 1: 150\end{array}$ & $\begin{array}{l}\text { Goat anti-rabbit-IgG- .Alexa Fluor 594 (A31631, Invitrogen) } \\
\text { Rabbit polyclonal anti-hAURORA B (ab2254, Abcam) } 1: 300\end{array}$ \\
$\begin{array}{l}\text { Rabbit polyclonal anti-mouseIgG-Alexa Fluor 488 (A31627, Invitrogen) } \\
\text { Goat anti-rabbit-IgG- .Alexa Fluor 594 (A31631, Invitrogen) }\end{array}$ \\
\hline
\end{tabular}

in p53-mutant tumour cells by the activation of meiotic proteins [24, 26, 27] and key self-renewal transcription factors (OCT4, NANOG, and SOX2) [28]. The majority of these polyploid cells senesce. However, a minor fraction retains divisional activities (thus counteracts or reverses senescence), accumulate self-renewal factors in their subnuclei, and subsequently undergo depolyploidisation to paradiploid descendants that provide clonogenic regrowth $[28,29]$.

Cycling tetraploidy, an illicit deviation from the normal cell cycle, is considered to serve as a crucial step from diploidy to cancer-related aneuploidy and from senescence to malignancy [17, 30-32]. Together, these data highlight the need to more closely investigate the role of endopolyploidy in the relationship between self-renewal and senescence. These investigations will greatly assist the current endeavours being made to induce reprogramming of somatic cells that are free from genomic damage and provide further information regarding the use of senescence-induction as a potential anticancer strategy $[33,34]$.

Therefore, we chose to examine these phenomena using a well-established model of cell senescence, involving in vitro cultured normal human fibroblast IMR90 cells. We show here that a small proportion of cells undergoing senescence are able to overcome the tetraploidy barrier and that these cells appear to simultaneously upregulate self-renewal and senescent factors.

\section{Materials and Methods}

2.1. Cell Culture. The wild-type p53 human embryo lung fibroblast cell line IMR90 was obtained from ATCC and also from Coriell collection kindly donated by Dr. A. Ivanov (Beatson Institute, Glasgow) after 21-23 population doublings (PDL). Cells were cultured in DMEM (Sigma) supplemented with 10\% FBS (Sigma), without antibiotics, as monolayers in a humidified incubator in 5\% $\mathrm{CO}_{2} / 95 \%$ air atmosphere. The early passage cells were split $1: 3(\sim 50$ $\times 10^{4}$ of cells per flask $\left(25 \mathrm{~cm}^{2}\right)$ twice weekly. Mid-passage cells were split 1:2 weekly, and late-passage cultures were split $1: 2$ once cultures attained confluence. Culture medium was changed two or three times between subculture. In this way, several subsequent passages were carried out until the cells failed to undergo $>0.8$ population doublings in a 7 -day culture period. Under the given conditions of cultivation, the cells typically reached this state after 40-50 PDL.

2.2. Immunofluorescence (IF). Cells were trypsinized, pelleted, washed in warm PBS, resuspended in FBS and cytospun on to polylysine-coated slides. For detailed cytological studies, the cells were also grown on glass cover slips. Cells on coverslips were rinsed in PBS and FBS, then fixed in methanol at $-20^{\circ} \mathrm{C}$ for $7 \mathrm{~min}(30 \mathrm{~min}$ for $\gamma-\mathrm{H} 2 \mathrm{AX}$ staining) followed by 10 short rinses in cold acetone at $-20^{\circ} \mathrm{C}$. Slides were washed in TBS/0.01\% Tween-20 (TBST) (0.05\% Tween-20 for $\gamma$-H2AX staining) three times for $5 \mathrm{~min}$ each, after which they were blocked with $1 \%$ bovine serum albumin in TBS/0.05\% Tween-20 for $15 \mathrm{~min}$. Fifty microliters of the appropriate dilution of antibody was applied to each sample and the slides incubated overnight at $4^{\circ} \mathrm{C}$. Samples were washed thrice for $5 \mathrm{~min}$ each time in TBST. The sources and dilutions of the primary and secondary antibodies are listed in Table 1. Poststaining was with DAPI $(0.25 \mu \mathrm{g} / \mathrm{mL})$. Cells were finally embedded in Prolong Gold (Invitrogen).

2.3. Microscopy. A fluorescence microscope (Leitz, Ergolux L03-10) equiped with a colour videocamera (Sony DXS500) was used to examine cell preparations, record images, and perform image cytometry. For three-colour images and colocalisation studies, the BRG filter system (Leica) providing nonoverlapping excitation and transmission emission of blue, red, and green bands was used. In addition, confocal microscopy (Leica, DM 600) was used with the images scanned in the three different colour channels in sequence.

2.4. DNA Image Cytometry. Cells grown on coverslips were rinsed in PBS and serum. Alternatively trypsinised cells were washed in warm PBS and suspended in FBS and cytospun onto glass slides. Both preparations were then fixed in ethanol/acetone $(1: 1, \mathrm{v} / \mathrm{v})$ overnight at $4^{\circ} \mathrm{C}$ and air dried. For stoichiometric DNA staining [35], slides were hydrolysed with $5 \mathrm{~N} \mathrm{HCl}$ for $20 \mathrm{~min}$ and stained with $0.05 \%$ toluidine blue in McIlvain 50\% buffer $\mathrm{pH} 4$ for $10 \mathrm{~min}$ at room temperature, rinsed, dehydrated in warm butanol, 


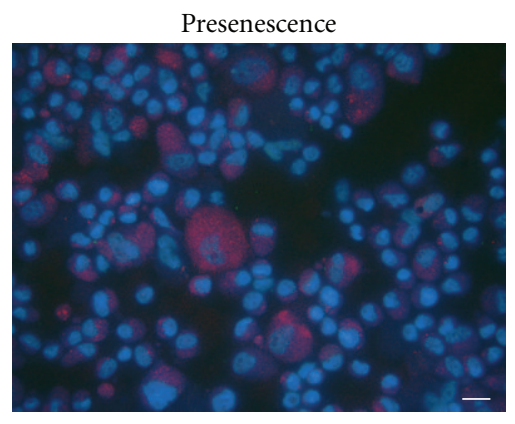

(a)

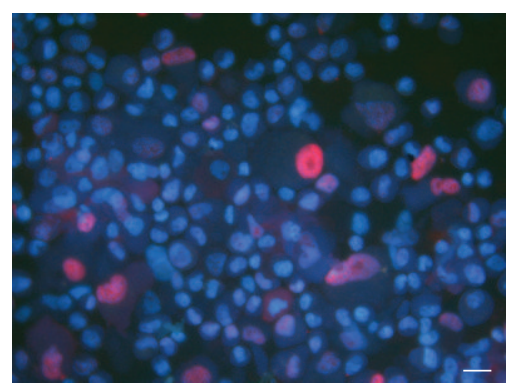

(d)

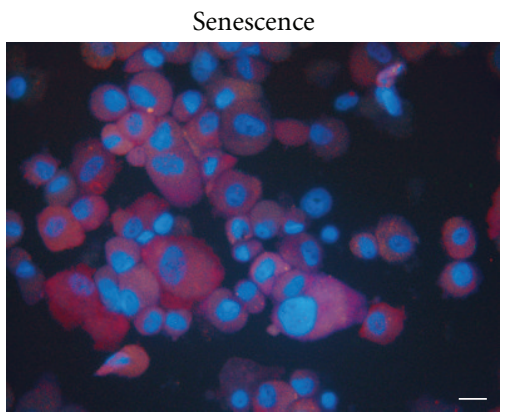

(b)

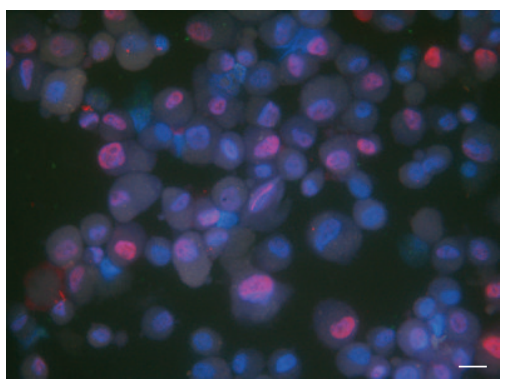

(e)

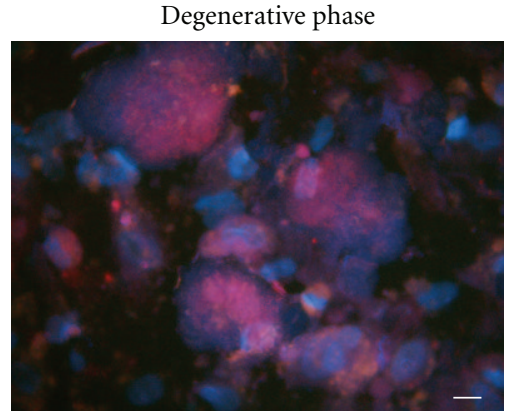

(c)

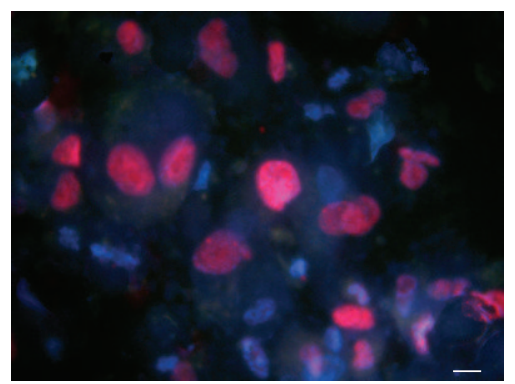

(f)

Figure 1: Phenotypic characteristics of IMR90 in the process of senescing showing cell enlargement and the accumulation of principal growth inhibitors involved in the regulation of senescence, p16 and p21, in three stages: ((a), (d)) presenescence, ((b), (e)) senescence, ((c), (f)) degeneration phase. ((a)-(c)) p16 (red) and DAPI (blue); ((d)-(f)) p21(red) and DAPI (blue). Scale bar $=20 \mu \mathrm{m}$.

and passed through xylene prior to embedding in DPX (Sigma-Aldrich). DNA content was measured as the integral optical density in 200 cell nuclei in the green channel of the calibrated video camera, using Image Pro Plus 4.1 software (Media Cybernetics; REO 2001, Latvia). In parallel, optical density and nuclear area were registered. The estimated sum of device and measurement error was $<5 \%$. The $2 \mathrm{C}$ DNA content was determined by the modal value of the first G1 peak. Mitotic indices were counted per 1,000-2,000 cells in the same samples.

2.5. RNA Extraction, RT-PCR, and DNA Sequencing of NANOG. These studies were performed on IMR90 cells in a logarithmic phase of growth as described before [28].

\section{Results}

3.1. Kinetics and Characteristics of Senescing Cells. Subcultivation of IMR90 cells invariably leads to diminishing growth after a number of passages. Under our experimental conditions, this was reached prematurely at passage $32-34$ corresponding to $40-50 \mathrm{PDL}$. This was likely due to growing the cells in the air atmosphere shortening their lifespan [36]. During further passaging, full growth arrest was achieved, characterised by the mitotic index reaching zero and the cells attaining typical features of senescence such as cytoplasm enlargement and flattening and bi- and multinuclearity, as well as accumulation of senescence markers p16inka4a (p16) and p21inka4a (p21) as illustrated on Figures 1(a), 1(b), 1(d), and 1(e). Degenerative phase was characterised by nuclear swelling and cell lysis (Figures 1(c) and 1(f)).

\subsection{DNA Cytometry Reveals a Minor Fraction of Cycling} Tetraploid Cells. As the cells underwent this senescence phenomenon, they were analysed by DNA image cytometry in three independent experimental series. The following cytometric regularities were observed. In the stage of logarithmic growth (typified in Figure 2(a)), where the mitotic index was $4.5-3.0 \%$, the cell population had a normal cell cycle, with typical DNA distribution of the major fractions between 2C and 4C. During presenescence, with the mitotic indices progressively lowering, the histogram of DNA distribution remained generally similar (exampled on Figure 2(b)), however the proportion of cells in the G1-2C phase increased and the S-phase decreased. At senescence, where no mitoses were observed, the proportion of interphase cells in the 4C-fraction was again increased (Figure 2(d)). This change was already noticeable at late presenescence, one-two passages earlier (Figure 2(c)). The average proportions of $4 \mathrm{C}$ cytometric fractions at the stages of logarithmic growth, presenescence and senescence, and corresponding proportions of the cells with p21-positive nuclei are presented on Figure 3.

In addition to the major DNA cytometric fractions, we also observed a small proportion (1-7\%) of hypertetraploid cells, some of them reaching octoploidy. The number of hypertetraploid cells strongly inversely correlated with mitotic indices in each experimental series (Figure 4(a)). Furthermore, the number of octoploid cells was found 


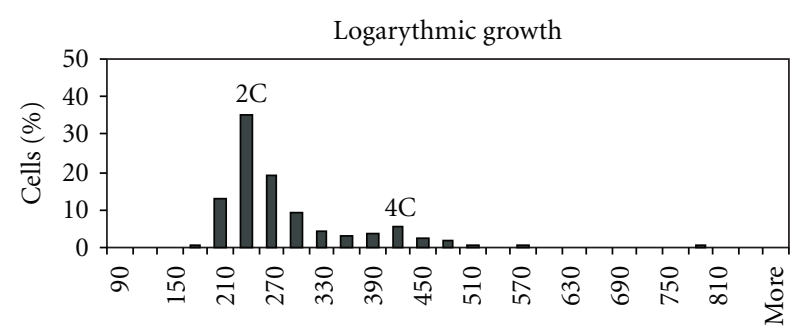

IOD (DNA content (a.u.))

(a)

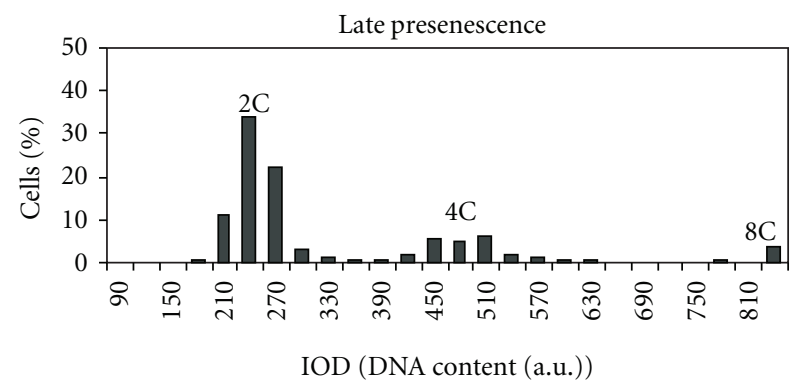

(c)

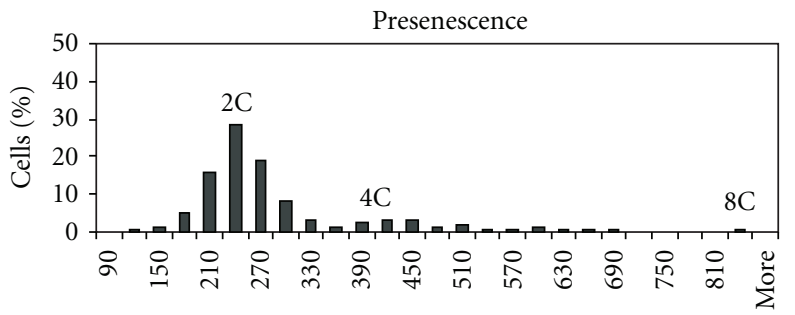

IOD (DNA content (a.u.))

(b)

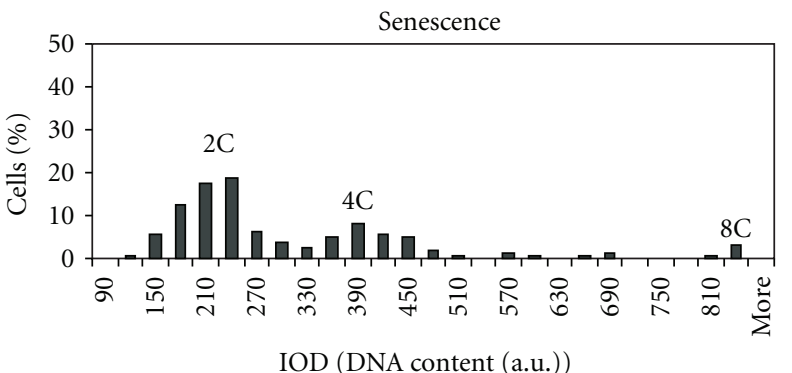

(d)

FIGURE 2: Histograms of IMR90 DNA content in several passages showing typical changes in the time course: (a) logarithmic growth, (b) presenescence, (c) late presenescence, and (d) senescence showing the accumulation of 4C cells and the increase of the proportion of hypertetraploid cells, some of which reach octoploidy.

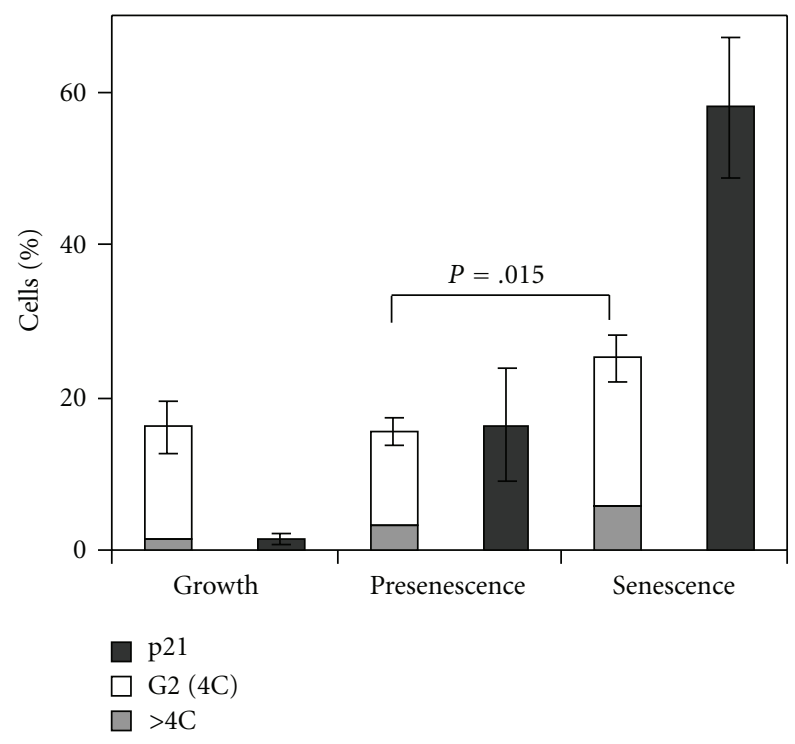

Figure 3: Quantitative data showing changes obtained from the DNA cytometry results, at the growth phase, presenescence, and senescence averaged from all experiments and the corresponding proportions of cells displaying nuclear positivity for $\mathrm{p} 21$. Significant increase of the $4 \mathrm{C}$ fraction accompany transition from presenescence to senescence $(P=.015)$. Increase of the proportion of hypertetraploid cells, in parallel to considerable increase of the proportion of p21-positive cells, accompany the whole process.

increasing with hypertetraploidy (Figure 4(b) and can be seen from Figure 2). These data indicate that the process of (accelerated) senescence encourages the cells to leave the normal cell cycle favouring their cycling as tetraploids.

\subsection{Self-Renewal Markers Appear at Presenescence in Tetrap-} loid Cells Simultaneously with Senescence and DDR Markers. We were further interested to see the association of these polyploid features with DDR, self-renewal, and senescence markers. At presenescence, we found that the embryonal transcription factors of pluripotency and self-renewal OCT4 (mostly cytoplasmic) and NANOG (nuclear) were activated in parallel with the initial activation of senescence factors in the same cells. Notably, this occurred in the cells with larger nuclei and larger (often polygonal) p16-positive cytoplasm, suggesting that these were hypertetraploid cells which had initiated the process towards senescence (illustrated in Figure 5). In an effort to better characterise the position of these particular cells in the cell cycle, we undertook two kinds of analysis.

First, we stained samples stoichiometrically with Toluidine blue for DNA and recorded the integral optical density (DNA content), nuclear area, and subsequently optical density (OD, concentration of DNA) of 200 cells in each sample using Image Pro Plus software. Importantly, this imaging method is interactive and excludes any cell aggregates, which are either excluded or separated for single cells before the measurement by the operator. Using this approach, the concentration of DNA remained constant in all samples (the data are not shown), with dispersion of $\mathrm{OD}$ around the average within only $2-3 \%$, up to the degeneration phase. The positive correlation between the DNA content per nucleus and its area counted for each sample is high $(r=0.57-0.76)$; 


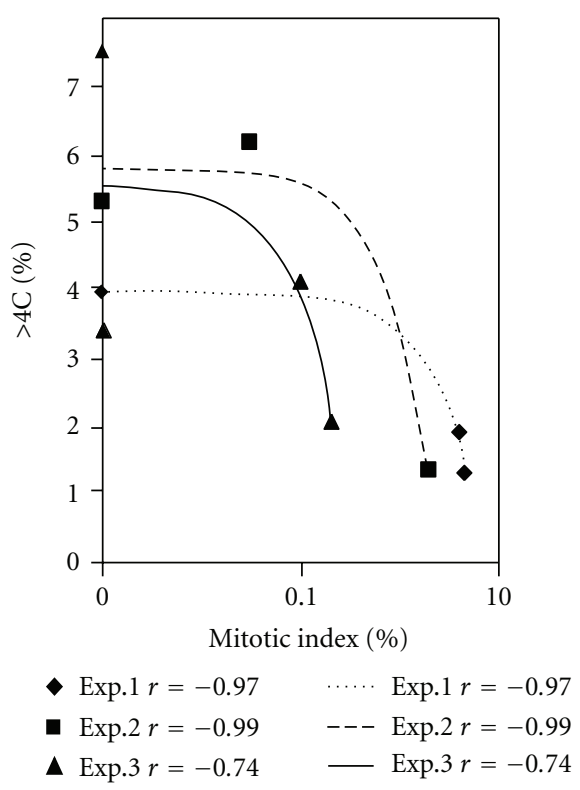

(a)

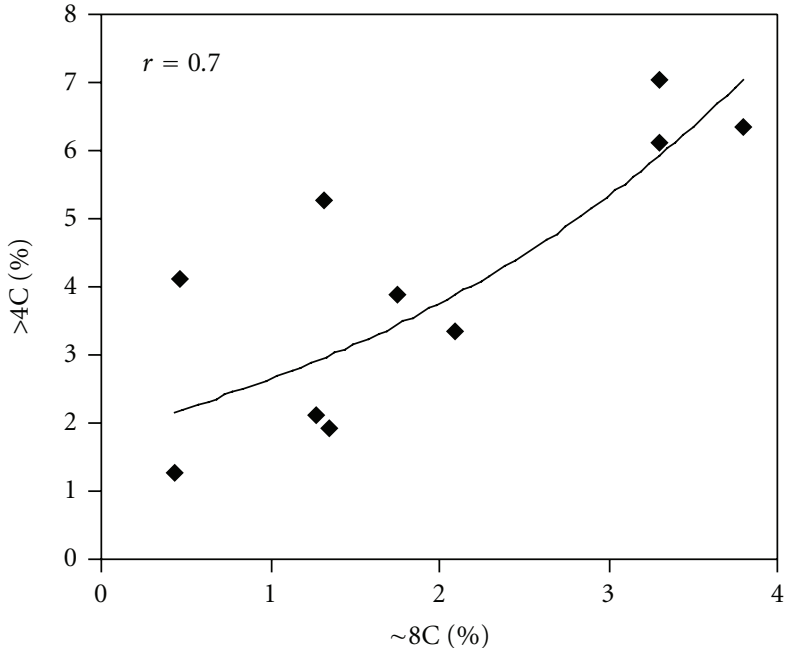

(b)

FIGURE 4: Tetraploidy increases in the course of IMR90 senescence. (a) The number of hypertetraploid cells increases with senescence and strongly inversely correlates with mitotic indices in each experimental series; (b) the number of cells with octoploid DNA content increases with hypertetraploidy indicating to increase of tetraploid cycling (the united data from three experiments).

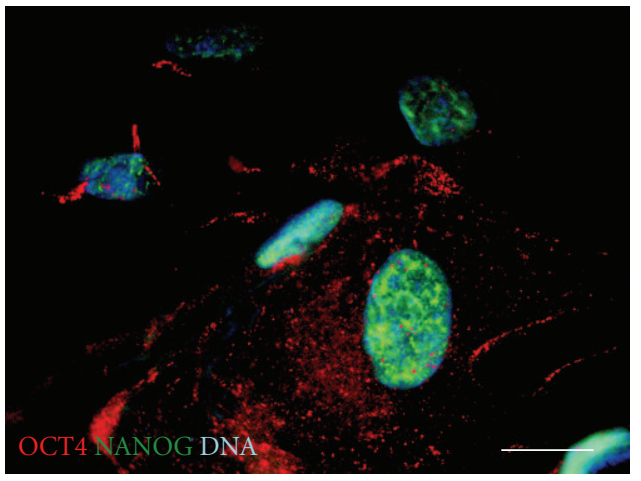

(a)

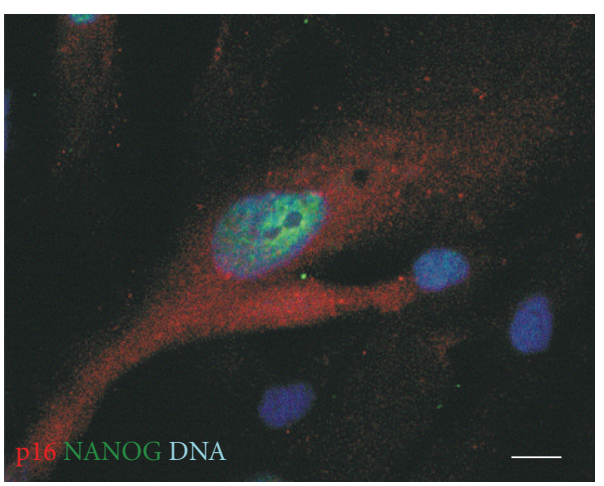

(b)

FIGURE 5: Examples of pre-senescent IMR90 fibroblasts grown on the coverslip, which differ from the surrounding cells by enlarged nuclei, cytoplasm volume, and the tendency of flattening. These cells express: (a) enhanced OCT4 (mostly in cytoplasm) and nuclear NANOG and (b) paranucleolarly localized NANOG, which is combined with enhanced expression of the senescence regulator, p16. Both, self-renewal and senescence regulators are undetectable or at the background level in the neighbouring fibroblasts possessing small nuclei. Scale bars $=10 \mu \mathrm{m}$. On (a) OCT4 was stained with the antibody for both A and B isoforms (Abcam polyclonal antibody, see Table 1).

an example is shown in Figure 6(a). This confirms the accepted observation that nuclear area is proportional to DNA content; hence, its concentration remains constant $[37,38]$. In Figure 6(a), sampled from presenescence phase, it is seen that the nuclear size of the $4 \mathrm{C}$ nuclei cluster is roughly twice as large as that of the $2 \mathrm{C}$ nuclei cluster, while the nuclear size of the cells with hypertetraploid DNA content exceeds that of the average $4 \mathrm{C}$ nuclei. It follows that the cells with a nuclear area visibly larger than that for G1 and G2 cells should contain the hypertetraploid DNA content.
Second, we stained samples for NANOG and one of the main senescence regulators (p16 or p21) in combination with DAPI. Using this approach, we identified cells possessing visibly larger nuclei as compared with G1- and G2-sized nuclei of surrounding fibroblasts which simultaneously expressed markers of both self-renewal (NANOG) and senescence. We subsequently applied DNA measurement of the integral nuclear fluorescence (INF) of these and neighbouring cell nuclei as exemplified on Figures 7(a) and 7(b), through 16 optical fields (total 242 cells); a selection of seven microscopic fields is also presented in supplemental 


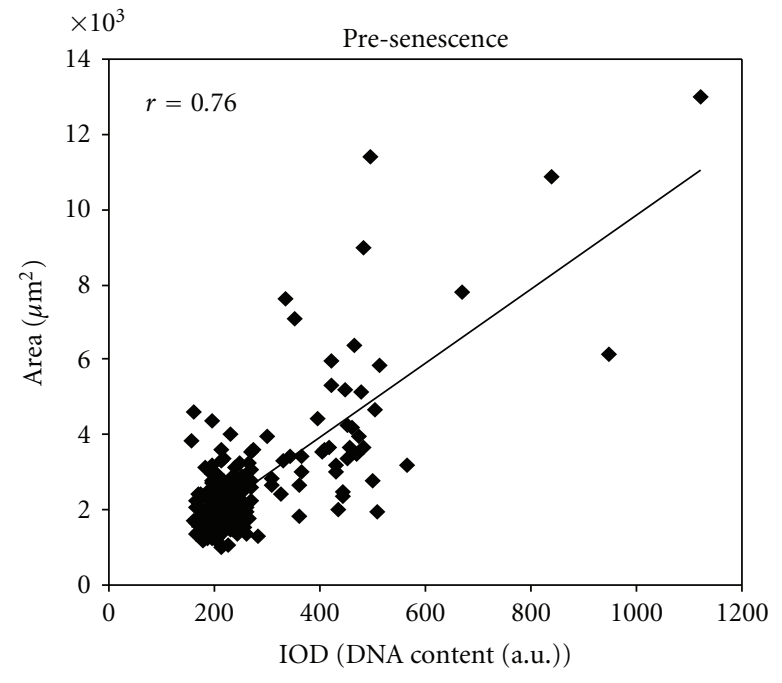

(a)

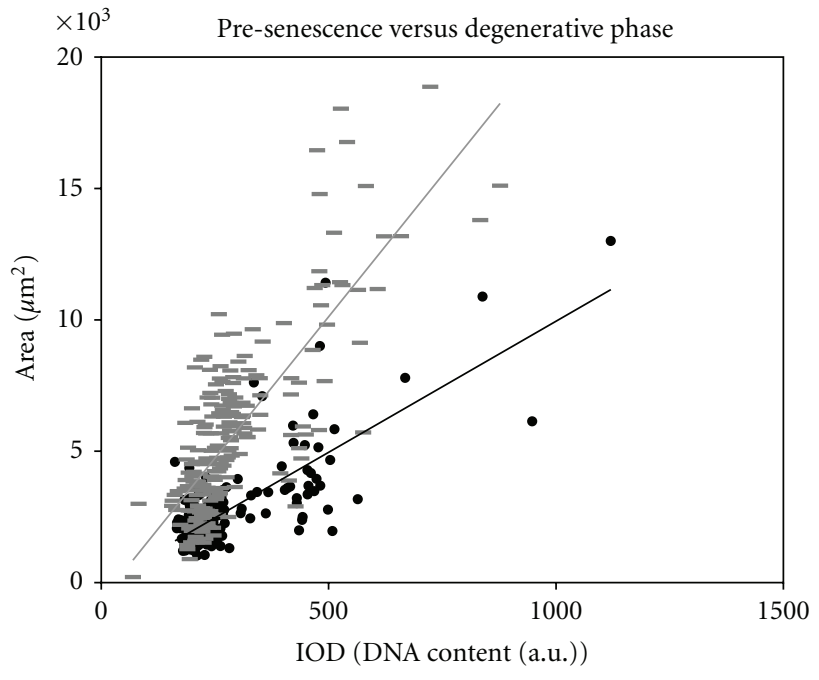

- Presenescence

Degenerative phase

(b)

FIGURE 6: The relationship between the nuclear area and the DNA content (IOD) per each cell nucleus in: (a) a typical sample of presenescence phase and (b) the comparison of the latter and a sample in the degeneration phase. It is seen that the nuclear size is increasing roughly proportionally to the DNA content in the presenescence phase, while in the degeneration phase, the nuclear size is much larger indicating to nuclear swelling.

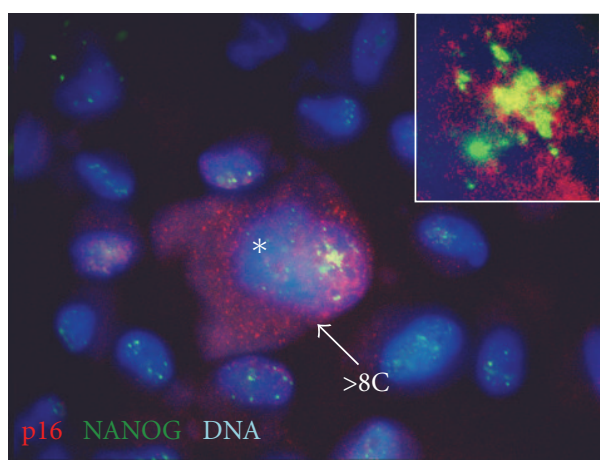

(a)

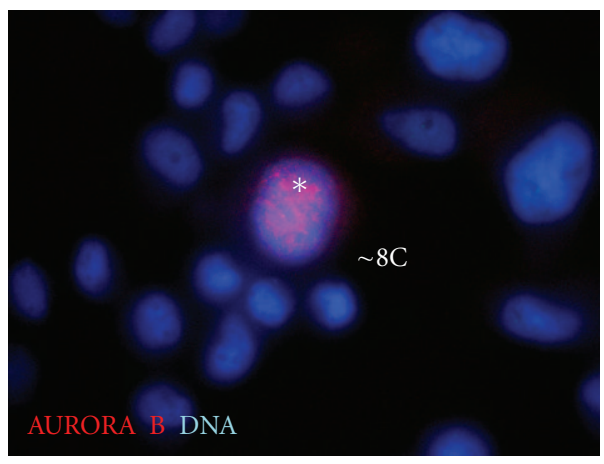

(c)

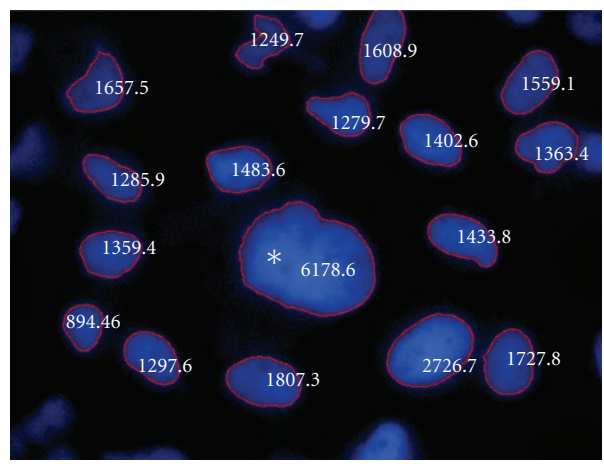

(b)

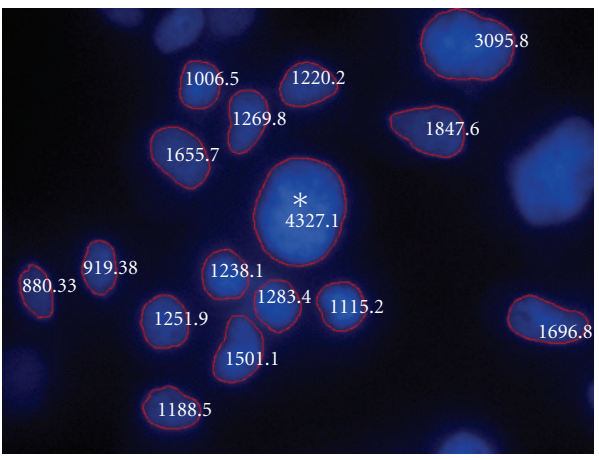

(d)

FIgURE 7: Examples of DNA content measurements by integral fluorescence in the DAPI channel using Image Pro Plus software in microscopic fields including cells with enlarged nuclei and stained for: ((a), (b)) NANOG, p16, and DNA by DAPI, ((c), (d)) Aurora Bkinase and DNA by DAPI. The selected hyperoctoploid cell $\left(^{*}\right)$ shown in (a) has an enlarged p16-positive cytoplasm and some amount of both NANOG and p16 in the nuclear region, and this region is magnified in the insertion; the paraoctoploid cell in (c) is positive for Aurora B-kinase. 


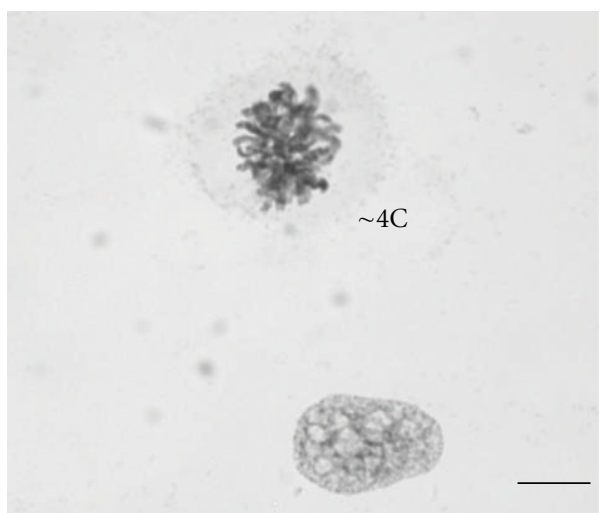

(a)

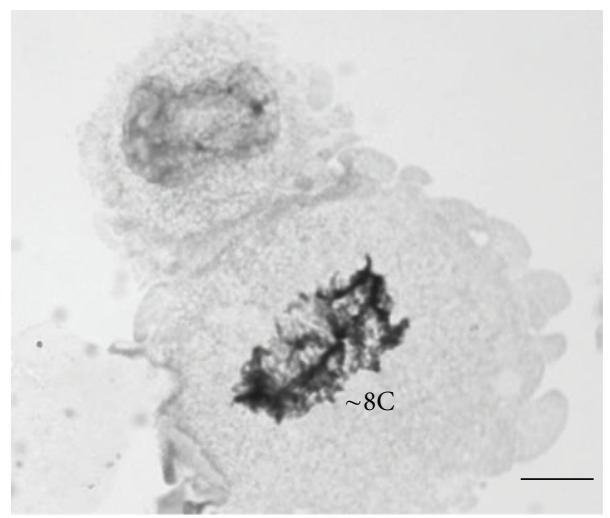

(c)

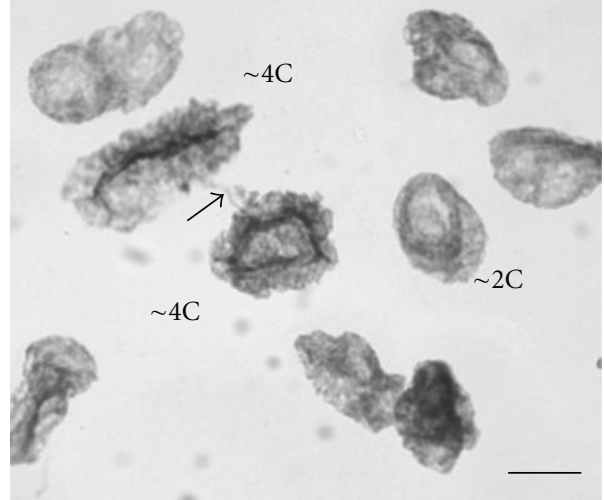

(b)

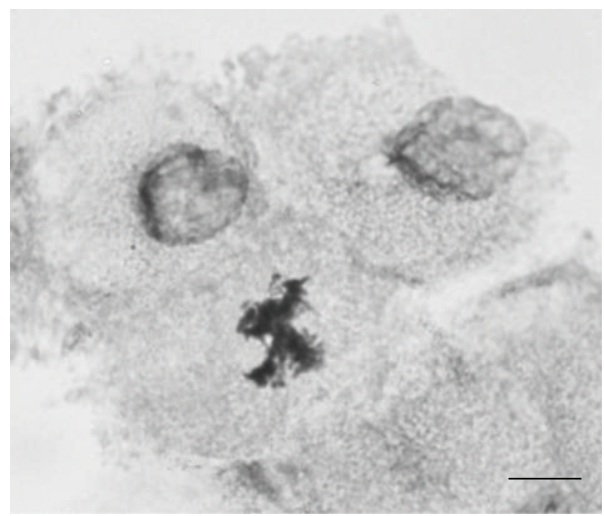

(d)

FIGURE 8: Mitoses of IMR90: (a) normal mitosis of a diploid cell in the growth stage, ((b)-(d)) mitoses in the presenescence stage. (b) Anaphase of the tetraploid cell, chromosome bridge (arrowhead) indicates to CIN. (c) Metaphase of the large tetraploid cell ( $\sim 8 C)$. (d) An attempt of the tetrapolar mitosis indicating to CIN. ((a),(b)) stoichiometric staining for DNA with Toluidine blue $\mathrm{pH} 4.0$ after extraction of RNA. ((c),(d)) Similar staining after partial extraction of RNA. Scale bar $=10 \mu \mathrm{m}$.

Figures 1-6 in Supplementary Material available online at doi: $10.4061 / 2011 / 103253$. The standard error of such nuclear measurements comparing the INF recorded on the smallest cell nuclei (2C-G1) was around 20\%. The selected cells which expressed markers of self-renewal and senescence contained tetraploid, hypertetraploid, or octoploid amounts of DNA more frequently than surrounding cells.

We were interested subsequently if these cells retained proliferation capacity. Using immunostaining for Aurora Bkinase as a marker of cell division potential for endopolyploid cells [39], we often found that cells with enlarged nuclei containing the tetraploid or octoploid amounts of DNA (as also detected in DAPI channel), were Aurora B-positive (exemplified on Figures 7(c) and 7(d)). At presenescence, we also found mitoses of tetraploid cells. Although commonly aberrant or pycnotic, some proceed to anaphase with signs of CIN such as chromosome bridges or multipolar mitoses (Figure 8).

The enlarged nuclei were also often labelled by the DDR marker $\gamma$-H2AX coupled to the NANOG staining (Figures 9(a) and 9(f)). Thus, at the presenescence stage, the cells with enlarged nuclei possessing enlarged p16-positive cytoplasm, simultaneously expressing small amounts of selfrenewal, senescence, and DDR markers in their nuclei were found to be tetraploid, had overcome the $4 n-G 1$ barrier, were cycling to octoploidy, and possessed division potential.

3.4. Self-Renewal, DDR, and Senescence Markers Are Initially Localised in the Perinucleolar Compartment of Tetraploid Cells. Interestingly, manifestations of all three kinds of response $(\gamma$-H2AX, NANOG, and p16/p21) were seen to be partialy colocalised as foci detected by BRG three-band optical filter (with nonoverlapping excitation and emission bands); and confirmed by confocal microscopy (supplemental Figure 7). These concentrated in the perinucleolar compartment either to one side of the large central nucleolus or surrounding it (Figures 9(a)-9(c)). Initial signs of senescence-associated heterochromatin foci (SAHF) also appear to emerge from the perinucleolar chromatin in such cells (Figure 9(d)). The initially observed PML-bodies, partially colocalised with $\gamma$-H2AX -positive speckles, were also found in this area (Figure 9(e)). The IMR90 cells at the logarithmic stage of growth had very low background IF staining for NANOG confirmed by RT-PCR and DNA sequencing (data not shown). The amount of NANOG usually seen by IF in 


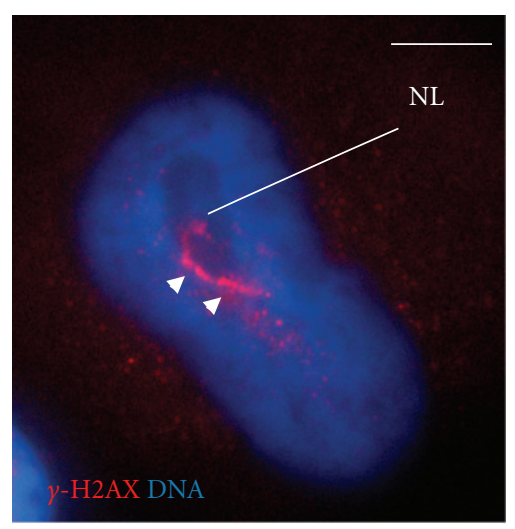

(a)

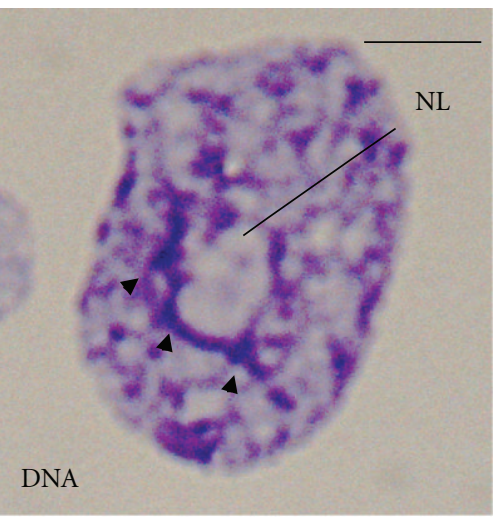

(d)

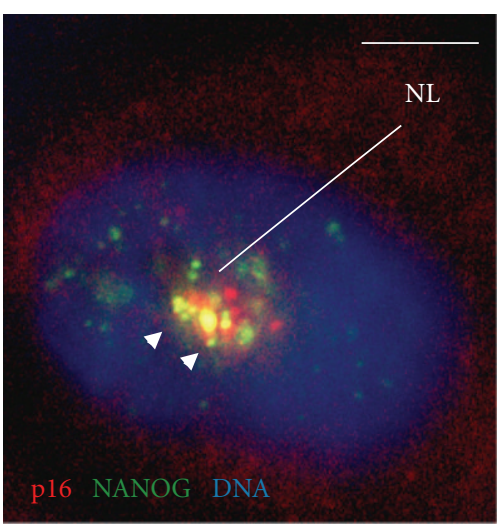

(b)

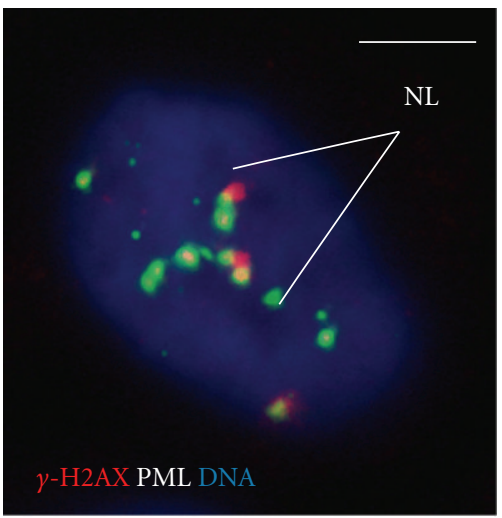

(e)

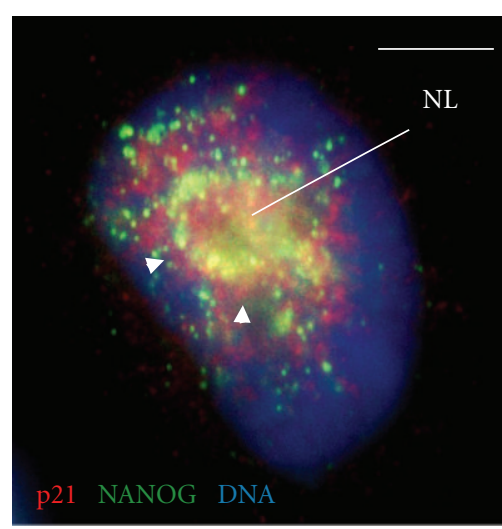

(c)

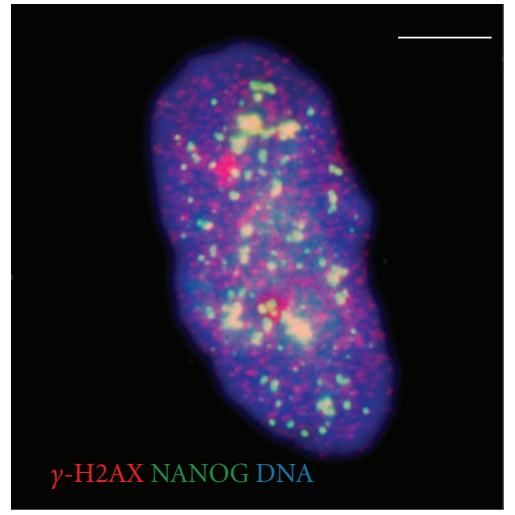

(f)

Figure 9: Characteristic cytological nuclear IF features of the tetraploid cells in the presenescence phase showing synergism of several labels located near the nucleoli. (a) Initial DDR in the perinucleolar chromatin indicated by the $\gamma$-H2AX-positive label (arrowheads), NLnucleolus. (b) The accumulation of p16 and NANOG-positive, partly colocalising granules in the perinucleolar region (arrowheads). (c) The accumulation of p21 and NANOG-partial colocalisation around the central nucleolus (arrowheads). (d) The emergence of initial gentle SAHFs revealed by DNA-specific metachromatic staining with Toluidine-blue in the perinucleolar chromatin (arrowheads). (e) PML bodies in the vicinity of the central lobulated nucleolus, where they partly colocalise with $\gamma$-H2AX-foci. (f) The tetraploid cell from the midpresenescence with the network of $\gamma$-H2AX and some amount of NANOG, partially colocalised. Images were obtained using BRG threecolour optical filters system. Scale bars $=10 \mu \mathrm{m}$.

the enlarged cell nuclei at early presenescence exceeded the background of surrounding cells with normal nuclei by $\sim 2-$ 4-fold (supplemental Figure 7).

We compared the frequency of this coexisting selfrenewal and senescence nuclear landmarks (mostly perinucleolar) in the cells with enlarged nuclei with that in the surrounding fibroblasts possessing normal 2C-4C-sized cell nuclei in one of early presenescence passages (Figure 11). From these counts, it can be seen that initial DDR and simultaneous senescence and self-renewal signalling were found in $84-96 \%$ of the cells with enlarged nuclei at far greater frequency (many-fold) than in the cells of the normal cell cycle. It should be stressed that it was practically impossible to find at this stage the cells where the nuclear enlargement and initial expression of DDR, NANOG, and senescence landmarks were dissociated. As such, also this approach confirmed that the expression of key markers of both senescence and pluripotency become selectively and simultaneously activated in tetraploid cells.
3.5. Through Intermediate Stage, NANOG Is Gradually Lost from Most Tetraploid Cell Nuclei, Correlating with an Accumulation of Senescence Markers during the Time Course of Senescence. Development of the tetraploid cells in subsequent passages of the culture as it progresses towards terminal senescence is characterised by the shaping of clear SAHFs, further increase of p16 in the enlarging cytoplasm, while smaller was this increase in the nuclei, and much stronger positivity of nuclear p21. p21 begins to extend from the perinucleolar region into the nucleoplasm (Figure 9(c)). Like p21, $\gamma$-H2AX also forms an elaborate network mostly in polyploid cells (Figure 9(f)). In these cells, NANOG can still be found, albeit in a more disseminated form, sometimes colocalised with regions of the p21 (Figure 9(c)) and $\gamma$ H2AX network (Figure 9(f)).

Figure 9(f) shows some intermediate state, when the both markers are still expressed. However, in mid-presenescence passages, $\gamma$-H2AX vanishes from the cells with the stronger expression of NANOG, and contrary to that, $2-3 \%$ of cells 


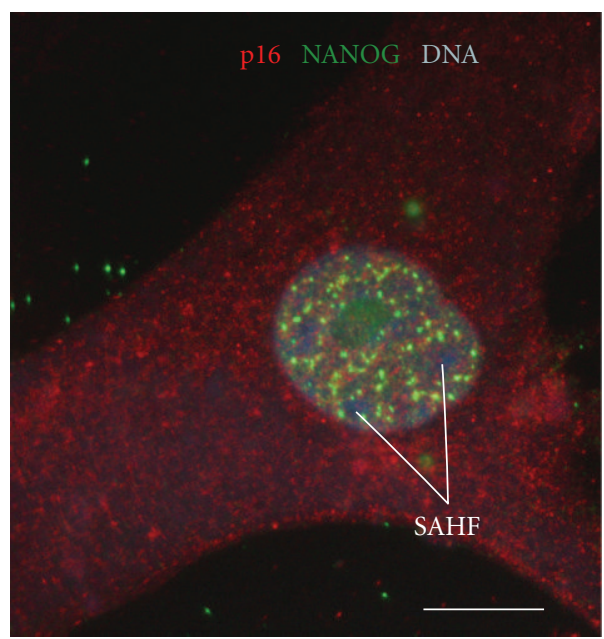

(a)

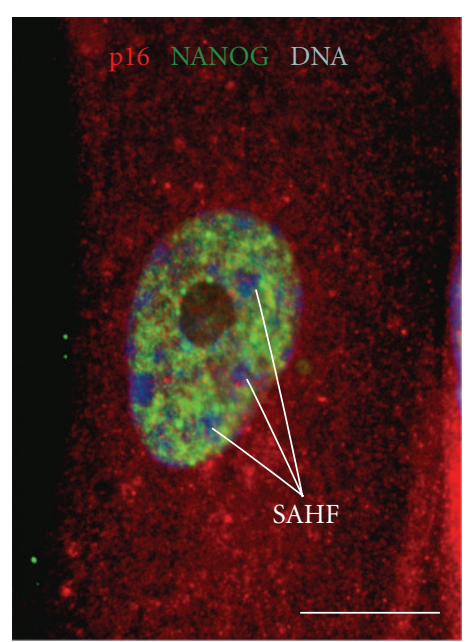

(b)

FIGURE 10: Relatively rare flattening giant fibroblasts displaying at presenescence a considerable accumulation of NANOG filling the whole nucleus in parallel to clear DAPI-positive SAHFs; in addition, the cells contain p16-positive material in the cytoplasm. Images were obtained using BRG three-colour optical filters system. Scale bars $=10 \mu \mathrm{m}$.

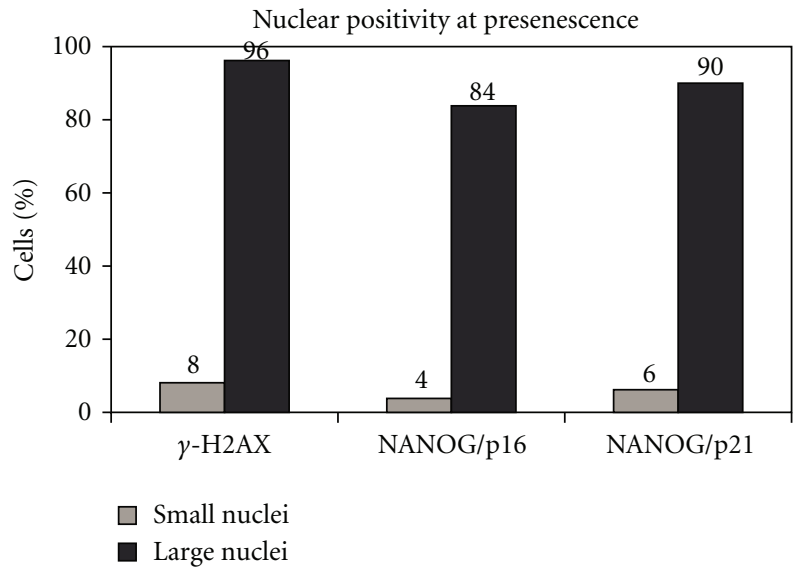

FIGURE 11: Proportions of the fibroblasts with enlarged (hypertetraploidy) nuclei and with conventional small nuclei in the early presenescence stage, estimated in one of the samples by the labelling frequency for $\gamma$-H2AX ( $n=400$ cells $)$, NANOG/p16 positive $(n=$ 300 cells), and NANOG/p21-positive nuclear granules $(n=300$ cells). All nuclear labels were mostly present in this phase in the perinucleolar region. Evaluation reveals a many-fold prevailing signalling for DDR, self-renewal, and senescence regulators occurring simultaneously in the enlarged hypertetraploidy cells, which left normal cell cycle.

which develop very clear thick $\gamma$-H2AX foci do not contain NANOG (not shown). The cells with large nuclei and stronger expression of NANOG are more notable in the "midpassages" of the presenescence (2-5\%), a few may accumulate it in their nuclei in the considerable amounts (Figure 10). However, the main tendency towards further senescing, contrary to the early phase of presenescence, when the initial expression of self-renewal and senescence markers appears positively linked, at more extended passages the expression of NANOG in the giant nuclei generally decreases proportionally to the accumulation of cytoplasmic p16 and of the enhanced nuclear expression of $p 21$, as illustrated on Figure 12.

In the very last passages, approaching terminal senescence with the mitotic index tending to zero $(<0.1 \%)$, this trend is further extended as illustrated in Figures 1(b), 1(c), $1(\mathrm{e})$, and 1(f), where the giant polyploid cells with large cytoplasm display considerable accumulation of p21 and p16. They are void of the NANOG expression or contain it at the background level. However, rare exceptions of the NANOG-positive cells with the only background expression of senescence factors were encountered (Figures 12(d)-12(e), arrowed). Further, the senescent cells appear to enter the terminal degeneration phase. Figures 1(c) and 1(f) show the appearance of cells at the terminal degeneration phase of the senescent culture, sampled from one typical experiment. These cells are characterised by the accumulation of p16 and p21 in the cell nuclei, absence of NANOG, lysis of the cytoplasm (Figures 1(c) and 1(f)), and by swelling of the nuclei as testified by DNA image cytometry presented in Figure 6(b).

\section{Discussion}

Here, we have documented the cellular behaviour of IMR90 cells as they undergo senescence after protracted in vitro culture. A notable observation in this process is the appearance of tetraploid cells. Clearly, tetraploid cells appearing in senescing cultures represent a deviation from normal cell cycle regulation. Such cells and their aberrant proliferative activities were reported from the very early studies of in vitro senescing cultures of normal fibroblasts occurring before terminal arrest of proliferation [6-8], and confirmed more recently [10]. Our results are entirely in accord with them. 


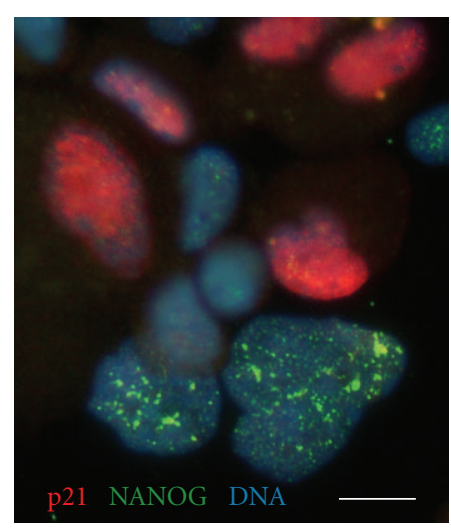

(a)

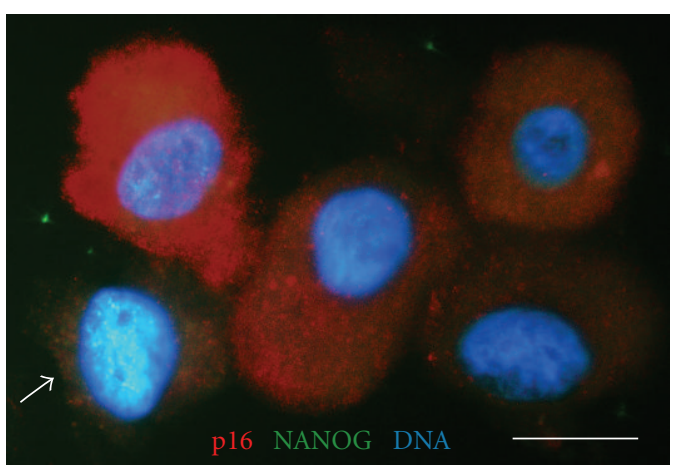

(d)

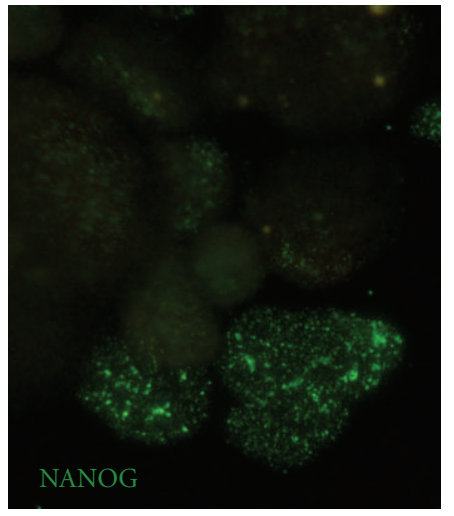

(b)

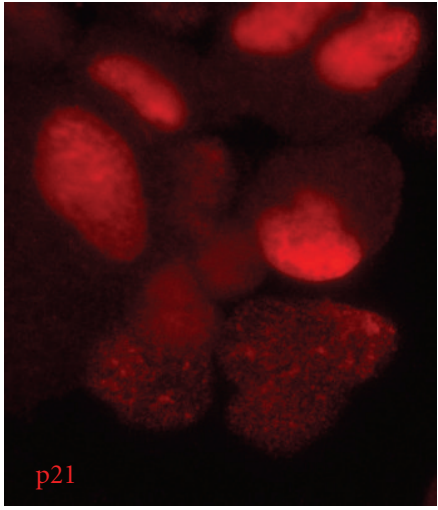

(c)

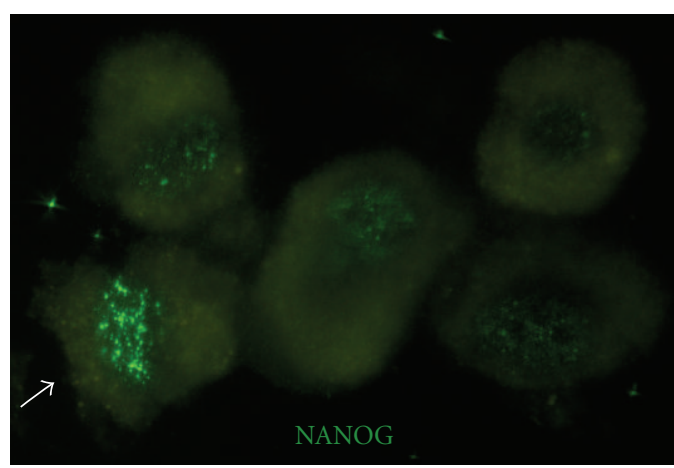

(e)

FIGURE 12: The antagonism between expression of NANOG and senescence regulators at the late presenescence and senescence phases: $((\mathrm{a})-(\mathrm{c}))$ late presenescence $(\mathrm{MI}=0.1 \%)$ : in the group of ten cells it is seen that nuclear staining of NANOG is found only in the cells with enlarged nuclei, where NANOG staining intensity is inverse to the staining for p21; ((d), (e)) senescence (MI = 0) - a rare NANOG-positive cell was encountered (arrowed), which has the weakest staining for p16 in its cytoplasm among five cells of the group. ((a), (d)) were imaged through the BRG filter; ((b), (e) )—through blue, and (c)—through green filter. Scale bars $=10 \mu \mathrm{m}$.

These deviations, indicative of chromosomal instability during presenescence, were shown to be related to telomeric dysfunction $[13-15,40]$.

It is difficult to judge to what extent the induction of polyploidy is associated with the stress due to in vitro cultivation. Previously, more stressful conditions of passage were shown to have a slight increase in polyploidy induction, although the same results could have been obtained, if more laboriously, from unstressed cells [10]. On the whole, our present data and that generated previously show that in the senescing culture, there is a tendency for a small proportion of normal human fibroblasts to increasingly form tetraploid cells, to cycle to octoploidy, and then divide. Cycling tetraploidy is generally considered as a dangerous step towards carcinogenesis as it brings CIN and can result in aneuploidy [30, 32]. It is known that functional p53/p21CIP1 should prevent tetraploidy at the $4 \mathrm{n}-\mathrm{G} 1 / \mathrm{S}$ checkpoint $[41$, 42], the existence of which was also disputed [16]. Our DNA cytometric data showed that at presenescence, this barrier is leaky and is linked to accumulation of $4 \mathrm{C}$ cells during the senescence process as the cells approach full growth arrest. The same increase in the $4 \mathrm{C}$ cell fraction in senescing IMR90 cells, then interpreted as arrest at the $4 \mathrm{n}$ G1 checkpoint, was previously reported by Sherwood and colleagues [43] following analysis by DNA flow cytometry and karyotyping and the same was found in an accelerated senescence model of Ras-oncogene transfected IMR90 cells [44].

In addition, we found here that illegitimate cycling of tetraploid cells at the early presenescence phase was associated with activation of the self-renewal response manifested by expression of the embryonal transcription factor NANOG. In our preliminary studies, we have also observed that the OCT4B splicing form (POU5F1_B) was activated; however, as its function is unknown, we concentrated here mostly on studies of NANOG expression.

The homeodomain gene, NANOG, is a key intrinsic determinant of self-renewal and pluripotency in embryonic stem cells. Beside its transactivation function, NANOG was also reported to directly propagate the G1-S transition by ativating cdk6 [45]. As the senescence regulator, p16 prevents endogenous Cdk6 and Cdk4 from associating with its catalytic unit cyclin D1 [46], NANOG should counteract this activity of p16. Moreover, normal embryonal stem cells in response to damage were shown to upregulate self-renewal transcription factors (Oct4 and Nanog) readily undergoing mitotic slippage and reversible tetraploidy [47]. Therefore, it remains possible that NANOG expression may force 
the normal fibroblasts (or their stem cells) in stressed senescing cultures to bypass this tetraploidy limiting control.

Our IF observations showed directly that NANOG is expressed in tetraploid cells of pre-senescing cultures unless the cells accumulate considerable amounts of senescence regulators (which occurs increasing as the cultures approach terminal senescence); in particular, clear antagonism was found at late passages between NANOG and accumulation of nuclear $\mathrm{p} 21$. These observations are entirely in line with the suggestion that $\mathrm{p} 16$ represents a second barrier to senescence, which in the absence of the main barrier p53/p21 may be reversible [48]. Our observations on more accumulation of NANOG in some tetraploid cells, which lose the DDR signalling in the intermediate presenescence stage, may be cautiously interpreted as tendency to revert senescence. It follows that at the presenescence phase, the amount of the p53/p21 growth inhibitor appears insufficient to downregulate NANOG, which may to some extent neutralise p16 and that, therefore, more time (or activation of more p53 activators including for example, the p38 pathway $[16,49])$ is needed for $\mathrm{p} 53$ to become an efficient enforcer of senescence barrier. This explanation of our observations is in line with the data that activated p53 suppresses the NANOG gene promoter [50].

Recently, Davoli and colleagues [40] showed that simultaneous elimination of telomerase and p53 causes chronic DDR resulting in the prolonged G2 arrest and tetraploidisation through licensing DNA rereplication origins. This data also well fit our observations as senescing is associated with telomere dysfunction (however, induction of self-renewal may counteract it by activating telomerase; this aspect needs further research), while found delay of p21 accumulation means relatively retarded activation of p53.

Although IMR90 are normal, nonmalignant cells containing wild-type p53, our observations importantly show for the first time that these normal cells can temporarily activate the self-renewal factor NANOG and enter "a window" when senescence regulators are as yet insufficiently active to irreversibly neutralise its activities. In line with this suggestion, upregulation of several embryonal pluripotency and self-renewal factors have also been reported by Riekstina and coauthors [51] in putative stem cells obtained from explanted adult human mesenchymal tissues during their first adaptive passages of in vitro cultivation. The step into tetraploidy is associated with DDR and genome instability, known to greatly increase the probability of chromosomal and genetic mutations and escape of revertants [30]. The same concern was formulated by Romanov et al. [19] and Walen [17], who showed that in presenescence the tetraploid cells display depolyploidisation activities and can ultimately escape senescence with a mutated genotype.

Although the IMR90 model is one of replicative or accelerated senescence in vitro, it has clear relevance to pathologic conditions in vivo where adult stem cells may be involved such as chronic inflammation and/or trauma.

However, a puzzle remains for the seemingly simultaneous initial induction of the opposing responses of DDR, selfrenewal, and senescence in the early pre-senescent tetraploid cells. The site of convergence may be the RAS-RAF-MEKERK pathway priming both the mitogenic and accelerated senescence pathways [52]. It was shown that moderate activation of the wild-type Ras is mitogenic, while overexpression causes p38-MAPK-dependent senescence [49]. This trigger leads, in particular, to positive versus negative regulation of Cyclin D1 [53], the catalytic unit of cdk6 activated by Nanog [45]. In the negative loop, suppression of Nanog by MEK-ERK was shown through chemical inhibition of MEK [54]. Clearly, the impact of the MEK/ERK pathway on NANOG and its role in the signalling of senescence require further attention.

The data, somewhat supportive for our observations, were reported by Banito and colleagues [55] who showed upregulation of cellular senescence by transduction in IMR90 cells of the four pluripotency-inducing oncogenes.

Interestingly, all three kinds of the initial response, selfrenewal, DDR and senescence, were found spatially confined to the perinucleolar compartment, and their partial or full colocalisation suggests a cross-talk between these pathways. Moreover, it is likely that the SAHFs which represent regions of epigenetically changed chromatin also start to form from the same region of the perinucleolar chromatin and are associated with the emergence of the DNA doublestrand breaks. The question is why these various aspects are appearing in the nucleolus.

The nucleolus is involved in the regulation of senescence in several ways. Nucleostemnin, a nucleolar protein specifically involved in regulating the cell cycle in stem and tumour cells, can sequestrate MDM2 and MDM4 and, thus, favour accumulation of p53, the main player in senescence induction $[56,57]$. Similarly nucleolar Arf will activate p53 in the senescence response [58]. In addition, relocation of hTERT to the nucleolus is associated with initiation of senescence [59]. Finally, PML binds MDM2 and sequesters it into the nucleolus [60], thus protecting p53 from proteosomemediated degradation.

However, the most important aspect may be that, in eukaryotic systems, rDNA contains fragile sites that are extremely sensitive to replication-induced stress [61, 62]. This replication stress may be related to the p53 independent license of rereplication origins fired at prolonged G2 arrest [40]. The level of the DNA Polymerase I in IMR90 tetraploid cells may be insufficient at this time-point, causing stalling of replication forks and converting the underreplicated sites into rDNA strandbreaks [63]. This idea is compatible with cancer development from its earliest stages being associated with DNA replication stress, leading to DNA strandbreaks and subsequently to DDR $[3,64,65]$.

In relation to p53-function-deficient tumours, our data $[28,29]$ also show that endopolyploid cells induced after genomic insult undertake sustainable activation of the pluripotency and self-renewal genes, and undergo a stage of competition between self-renewal and senescence with an improved chance for self-renewal to succeed. A proportion of these p53-mutated polyploid cells is capable of accumulating considerable amounts of self-renewal factors and subsequently depolyploidise into mitotic paradiploid descendants. 


\section{Conclusion}

Our findings on senescing normal human IMR90 fibroblasts clearly provide us with insight into the risks of cancer development. Since it is assumed that a cancer clone develops from a single adult stem cell which receives a mutation(s), including those compromising the senescence barrier, our observations suggest that this may be favoured in the normal stressed tissue due to the unique cellular and molecular setting of the presenescence stage. It is hypothesised that telomere dysfunction causing DDR and temporary activation of self-renewal on a background of insufficient activity of senescence inducers may allow putative adult stem cells to overcome the G1 tetraploidy limit controlled by p53 leading to their replicative stress and aberrant divisions. This would favour acquisition of CIN, aneuploidy, and tumorigenic mutations, thereby driving tumorigenesis.

\section{Conflict of Interests}

The authors declare no conflict of interests.

\section{Authors Contribution}

A. Huna performed DNA image cytometry, participated in design and analysis of experiments and editing of the manuscript; K. Salmina performed immunofluorescence stainings, participated in design and analysis of experiments and editing of the MS; E. Jascenko carried out cell cultures, participated in design and analysis of experiments; G. Duburs participated in design and analysis of experiments; I. Inashkina performed RT-PCR with sequence analysis of NANOG expression, participated in design and analysis of experiments and editing of the MS; J. Erenpreisa designed experiments, performed microscopy and analysis of results and prepared the draft and editing of the manuscript, A. Huna and K. Salmina made an equal contribution.

\section{Acknowledgments}

The authors are thankful to Dr. Andrey Ivanov (Beatson Institute, Glazgow) for donating IMR90 cells, Dr. Talivaldis Freivalds for DAPI measurements, Professor Denys Wheatley for reading, to Professor Mark S Cragg and Dr. Karina Silina for English editing of the manuscript, and Pawel Zajakin for help in formatting the pictures. This study was supported by the ESF Grant no. 2009/0204/1DP/1.1.1.2.0/09/APIA/VIA/150, and by the European Social Fund within the project "Support for Doctoral Studies at University of Latvia”.

\section{References}

[1] J. W. Shay and I. B. Roninson, "Hallmarks of senescence in carcinogenesis and cancer therapy," Oncogene, vol. 23, no. 16, pp. 2919-2933, 2004.

[2] F. D’Adda Di Fagagna, "Living on a break: cellular senescence as a DNA-damage response," Nature Reviews Cancer, vol. 8, no. 7, pp. 512-522, 2008.
[3] D. W. Meek, "Tumour suppression by p53: a role for the DNA damage response?" Nature Reviews Cancer, vol. 9, no. 10, pp. 714-723, 2009.

[4] T. Finkel, M. Serrano, and M. A. Blasco, "The common biology of cancer and ageing," Nature, vol. 448, no. 7155, pp. 767-774, 2007.

[5] M. Collado and M. Serrano, "Senescence in tumours: evidence from mice and humans," Nature Reviews Cancer, vol. 10, no. 1, pp. 51-57, 2010.

[6] L. Hayflick and P. S. Moorhead, "The serial cultivation of human diploid cell strains," Experimental Cell Research, vol. 25, no. 3, pp. 585-621, 1961.

[7] E. Saksela and P. S. Moorhead, "Aneuploidy in the degenerative phase of serial cultivation of human cell strains," Proceedings of the National Academy of Sciences of the United States of America, vol. 50, pp. 390-395, 1963.

[8] B. A. Houghton and G. H. Stidworthy, "A growth history comparison of the human diploid cells WI-38 and IMR-90: proliferative capacity and cell sizing analysis," In Vitro, vol. 15, no. 9, pp. 697-702, 1979.

[9] K. H. Walen, "Budded karyoplasts from multinucleated fibroblast cells contain centrosomes and change their morphology to mitotic cells," Cell Biology International, vol. 29, no. 12, pp. 1057-1065, 2005.

[10] K. H. Walen, "Human diploid fibroblast cells in senescence; cycling through polyploidy to mitotic cells," In Vitro Cellular and Developmental Biology, vol. 42, no. 7, pp. 216-224, 2006.

[11] K. H. Walen, "Origin of diplochromosomal polyploidy in near-senescent fibroblast cultures: heterochromatin, telomeres and chromosomal instability (CIN)," Cell Biology International, vol. 31, no. 12, pp. 1447-1455, 2007.

[12] K. H. Walen, "Bipolar genome reductional division of human near-senescent, polyploid fibroblast cells," Cancer Genetics and Cytogenetics, vol. 173, no. 1, pp. 43-50, 2007.

[13] C. B. Harley, "Telomere loss: mitotic clock or genetic time bomb?" Mutation Research, vol. 256, no. 2-6, pp. 271-282, 1991.

[14] J. R. Smith and O. M. Pereira-Smith, "Replicative senescence: implications for in vivo aging and tumor suppression," Science, vol. 273, no. 5271, pp. 63-67, 1996.

[15] R. A. DePinho, “The age of cancer," Nature, vol. 408, no. 6809, pp. 248-254, 2000.

[16] N. J. Ganem and D. Pellman, "Limiting the proliferation of polyploid cells," Cell, vol. 131, no. 3, pp. 437-440, 2007.

[17] K. H. Walen, "Genetic stability of senescence reverted cells: genome reduction division of polyploidy cells, aneuploidy and neoplasia," Cell Cycle, vol. 7, no. 11, pp. 1623-1629, 2008.

[18] E. M. Torres, N. Dephoure, A. Panneerselvam et al., "Identification of aneuploidy-tolerating mutations," Cell, vol. 143, no. 1, pp. 71-83, 2010.

[19] S. R. Romanov, B. K. Kozakiewicz, C. R. Holst, M. R. Stampfer, L. M. Haupt, and T. D. Tlsty, "Normal human mammary epithelial cells spontaneously escape senescence and acquire genomic changes," Nature, vol. 409, no. 6820, pp. 633-637, 2001.

[20] M. L. Friedlander, D. W. Hedley, and I. W. Taylor, "Clinical and biological significance of aneuploidy in human tumours," Journal of Clinical Pathology, vol. 37, no. 9, pp. 961-974, 1984.

[21] T. M. Illidge, M. S. Cragg, B. Fringes, P. Olive, and J. A. Erenpreisa, "Polyploid giant cells provide a survival mechanism for p53 mutant cells after DNA damage," Cell Biology International, vol. 24, no. 9, pp. 621-633, 2000. 
[22] M. Sundaram, D. L. Guernsey, M. M. Rajaraman, and R. Rajaraman, "Neosis: a novel type of cell division in cancer," Cancer Biology and Therapy, vol. 3, no. 2, pp. 207-218, 2004.

[23] P. E. Puig, M. N. Guilly, A. Bouchot et al., "Tumor cells can escape DNA-damaging cisplatin through DNA endoreduplication and reversible polyploidy," Cell Biology International, vol. 32, no. 9, pp. 1031-1043, 2008.

[24] I. Vitale, L. Senovilla, M. Jema et al., "Multipolar mitosis of tetraploid cells: inhibition by p53 and dependency on Mos," EMBO Journal, vol. 29, no. 7, pp. 1272-1284, 2010.

[25] I. B. Roninson, "Tumor cell senescence in cancer treatment," Cancer Research, vol. 63, no. 11, pp. 2705-2715, 2003.

[26] J. Erenpreisa, M. S. Cragg, K. Salmina, M. Hausmann, and H. Scherthan, "The role of meiotic cohesin REC8 in chromosome segregation in $\gamma$ irradiation-induced endopolyploid tumour cells," Experimental Cell Research, vol. 315, no. 15, pp. 2593 2603, 2009.

[27] F. Ianzini, E. A. Kosmacek, E. S. Nelson et al., "Activation of meiosis-specific genes is associated with depolyploidization of human tumor cells following radiation-induced mitotic catastrophe," Cancer Research, vol. 69, no. 6, pp. 2296-2304, 2009.

[28] K. Salmina, E. Jankevics, A. Huna et al., "Up-regulation of the embryonic self-renewal network through reversible polyploidy in irradiated p53-mutant tumour cells," Experimental Cell Research, vol. 316, no. 13, pp. 2099-2112, 2010.

[29] J. Erenpreisa, K. Salmina, A. Huna et al., "Polyploid tumour cells elicit para-diploid progeny through de-polyploidisation divisions and regulated autophagy," Cell Biology International, 2011.

[30] Z. Storchova and D. Pellman, "From polyploidy to aneuploidy, genome instability and cancer," Nature Reviews Molecular Cell Biology, vol. 5, no. 1, pp. 45-54, 2004.

[31] G. Mosieniak and E. Sikora, "Polyploidy: the link between senescence and cancer," Current Pharmaceutical Design, vol. 16, no. 6, pp. 734-740, 2010.

[32] M. Castedo, I. Vitale, and G. Kroemer, "A novel source of tetraploid cancer cell precursors: telomere insufficiency links aging to oncogenesis," Oncogene, vol. 29, no. 44, pp. 5869$5872,2010$.

[33] A. Carnero, "Targeting the cell cycle for cancer therapy," British Journal of Cancer, vol. 87, no. 2, pp. 129-133, 2002.

[34] M. Vergel, J. J. Marin, P. Estevez, and A. Carnero, "Cellular senescence as a target in cancer control," Journal of Aging Research, vol. 2011, Article ID 725365, 12 pages, 2011.

[35] J. Erenpreisa and T. Freivalds, "Anisotropic staining of apurinic acid with toluidine blue," Histochemistry, vol. 60, no. 3, pp. 321-325, 1979.

[36] Q. Chen, A. Fischer, J. D. Reagan, L. J. Yan, and B. N. Ames, "Oxidative DNA damage and senescence of human diploid fibroblast cells," Proceedings of the National Academy of Sciences of the United States of America, vol. 92, no. 10, pp. 4337-4341, 1995.

[37] E. Therman and M. Susman, Human Chromosomes: Structure, Behaviour, and Effects, Springer, New York, NY, USA, 1973.

[38] C. J. Epstein, "Cell size, nuclear content and the development of polyploidy in the mammalian liver," Proceedings of the National Academy of Sciences of the United States of America, vol. 57, pp. 327-334, 1967.

[39] J. Erenpreisa, A. Ivanov, S. P. Wheatley et al., "Endopolyploidy in irradiated p53-deficient tumour cell lines: persistence of cell division activity in giant cells expressing Aurora-B kinase," Cell Biology International, vol. 32, no. 9, pp. 1044-1056, 2008.
[40] T. Davoli, E. L. Denchi, and T. de Lange, "Persistent telomere damage induces bypass of mitosis and tetraploidy," Cell, vol. 141, no. 1, pp. 81-93, 2010.

[41] P. R. Andreassen, F. B. Lacroix, O. D. Lohez, and R. L. Margolis, "Neither p21 nor 14-3-3 $\sigma$ prevents G progression to mitotic catastrophe in human colon carcinoma cells after DNA damage, but p21 induces stable $\mathrm{G}$ arrest in resulting tetraploid cells," Cancer Research, vol. 61, no. 20, pp. 7660-7668, 2001.

[42] R. L. Margolis, "Tetraploidy and tumor development," Cancer Cell, vol. 8, no. 5, pp. 353-354, 2005.

[43] S. W. Sherwood, D. Rush, J. L. Ellsworth, and R. T. Schimke, "Defining cellular senescence in IMR-90 cells: a flow cytometric analysis," Proceedings of the National Academy of Sciences of the United States of America, vol. 85, no. 23, pp. 9086-9090, 1988.

[44] D. X. Mason, T. J. Jackson, and A. W. Lin, "Molecular signature of oncogenic ras-induced senescence," Oncogene, vol. 23, no. 57, pp. 9238-9246, 2004.

[45] X. Zhang, I. Neganova, S. Przyborski et al., "A role for NANOG in G1 to $S$ transition in human embryonic stem cells through direct binding of CDK6 and CDC25A," Journal of Cell Biology, vol. 184, no. 1, pp. 67-82, 2009.

[46] R. Fåhraeus, S. Laín, K. L. Ball, and D. P. Lane, "Characterization of the cyclin-dependent kinase inhibitory domain of the INK4 family as a model for a synthetic tumour suppressor molecule," Oncogene, vol. 16, no. 5, pp. 587-596, 1998.

[47] C. Mantel, Y. Guo, R. L. Man et al., "Checkpoint-apoptosis uncoupling in human and mouse embryonic stem cells: a source of karyotpic instability," Blood, vol. 109, no. 10, pp. 4518-4527, 2007.

[48] C. M. Beauséjour, A. Krtolica, F. Galimi et al., "Reversal of human cellular senescence: roles of the p53 and p16 pathways," EMBO Journal, vol. 22, no. 16, pp. 4212-4222, 2003.

[49] Q. Deng, R. Liao, B. L. Wu, and P. Sun, "High intensity ras signaling induces premature senescence by activating $\mathrm{p} 38$ pathway in primary human fibroblasts," Journal of Biological Chemistry, vol. 279, no. 2, pp. 1050-1059, 2004.

[50] T. Lin, C. Chao, S. Saito et al., "p53 induces differentiation of mouse embryonic stem cells by suppressing Nanog expression," Nature Cell Biology, vol. 7, no. 2, pp. 165-171, 2005.

[51] U. Riekstina, I. Cakstina, V. Parfejevs et al., "Embryonic stem cell marker expression pattern in human mesenchymal stem cells derived from bone marrow, adipose tissue, heart and dermis," Stem Cell Reviews and Reports, vol. 5, no. 4, pp. 378386, 2010.

[52] A. W. Lin, M. Barradas, J. C. Stone, L. Van Aelst, M. Serrano, and S. W. Lowe, "Premature senescence involving p53 and p16 is activated in response to constitutive MEK/MAPK mitogenic signaling," Genes and Development, vol. 12, no. 19, pp. 30083019, 1998.

[53] J. N. Lavoie, G. L’Allemain, A. Brunei, R. Müller, and J. Pouysségur, "Cyclin D1 expression is regulated positively by the p42/p44(MAPK) and negatively by the p38/HOG(MAPK) pathway," Journal of Biological Chemistry, vol. 271, no. 34, pp. 20608-20616, 1996.

[54] T. Hamazaki, S. M. Kehoe, T. Nakano, and N. Terada, "The Grb2/Mek pathway represses nanog in murine embryonic stem cells," Molecular and Cellular Biology, vol. 26, no. 20, pp. 7539-7549, 2006.

[55] A. Banito, S. T. Rashid, J. C. Acosta et al., "Senescence impairs successful reprogramming to pluripotent stem cells," Genes and Development, vol. 23, no. 18, pp. 2134-2139, 2009. 
[56] R. Y. L. Tsai and R. D. G. McKay, "A nucleolar mechanism controlling cell proliferation in stem cells and cancer cells," Genes and Development, vol. 16, no. 23, pp. 2991-3003, 2002.

[57] H. Ma and T. Pederson, "Nucleophosmin is a binding partner of nucleostemin in human osteosarcoma cells," Molecular Biology of the Cell, vol. 19, no. 7, pp. 2870-2875, 2008.

[58] J. D. Weber, L. J. Taylor, M. F. Roussel, C. J. Sherr, and D. Bar-Sagi, "Nucleolar Arf sequesters Mdm2 and activates p53," Nature Cell Biology, vol. 1, no. 1, pp. 20-26, 1999.

[59] J. Huang, J. Lin, R. Jin et al., "Relocation of hTERT from nucleoplasm to nucleoli induces cancer cells senescence without affecting telomerase activity," AACR Meeting Abstracts, 2005, abstracts 1022 .

[60] R. Bernardi, P. P. Scaglioni, S. Bergmann, H. F. Horn, K. H. Vousden, and P. P. Pandolfi, "PML regulates p53 stability by sequestering Mdm2 to the nucleolus," Nature Cell Biology, vol. 6, no. 7, pp. 665-672, 2004.

[61] T. W. Glover, C. Berger, J. Coyle, and B. Echo, "DNA polymerase $\alpha$ inhibition by aphidicolin induces gaps and breaks at common fragile sites in human chromosomes," Human Genetics, vol. 67, no. 2, pp. 136-142, 1984.

[62] J. Z. Torres, J. B. Bessler, and V. A. Zakian, "Local chromatin structure at the ribosomal DNA causes replication fork pausing and genome instability in the absence of the $S$. cerevisiae DNA helicase Rrm3p," Genes and Development, vol. 18, no. 5, pp. 498-503, 2004.

[63] A. M. Casper, P. A. Mieczkowski, M. Gawel, and T. D. Petes, "Low levels of DNA polymerase alpha induce mitotic and meiotic instability in the ribosomal DNA gene cluster of Saccharomyces cerevisiae," PLoS Genetics, vol. 4, no. 6, article e1000105, 2008.

[64] V. G. Gorgoulis, L. V. F. Vassiliou, P. Karakaidos et al., "Activation of the DNA damage checkpoint and genomic instability in human precancerous lesions," Nature, vol. 434, no. 7035, pp. 907-913, 2005.

[65] J. Bartkova, Z. Hořejší, K. Koed et al., "DNA damage response as a candidate anti-cancer barrier in early human tumorigenesis," Nature, vol. 434, no. 7035, pp. 864-870, 2005. 


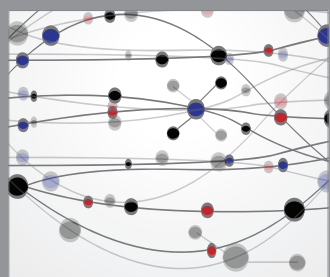

The Scientific World Journal
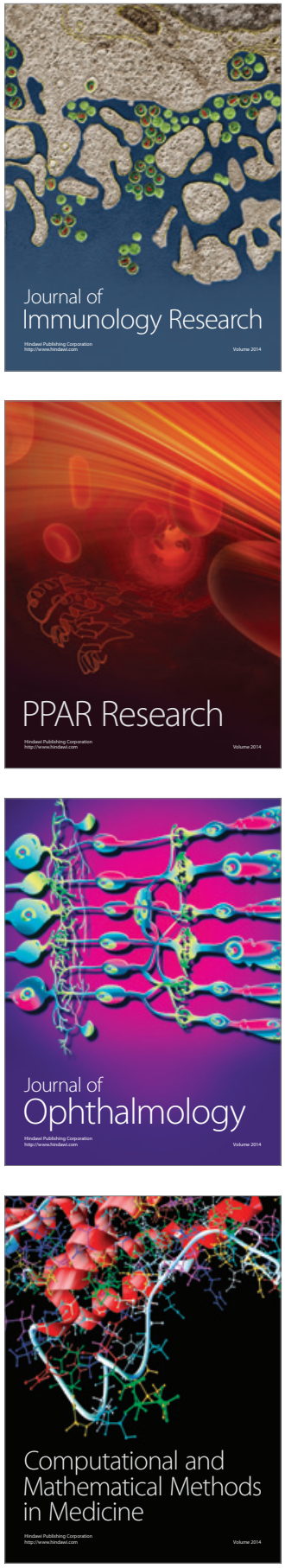

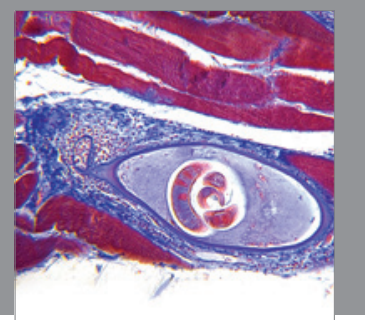

Gastroenterology

Research and Practice
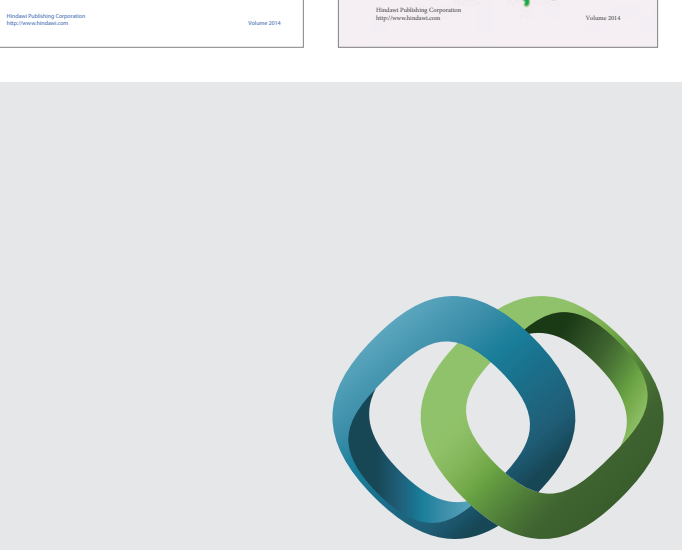

\section{Hindawi}

Submit your manuscripts at

http://www.hindawi.com
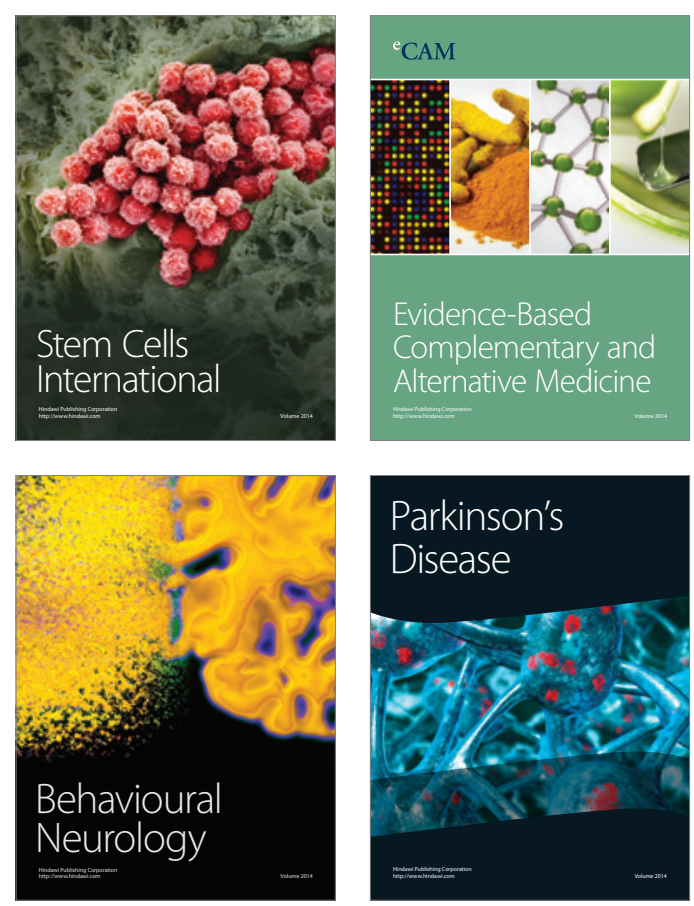

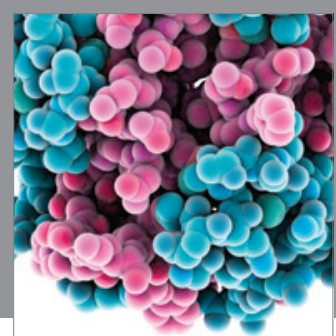

Journal of
Diabetes Research

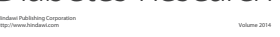

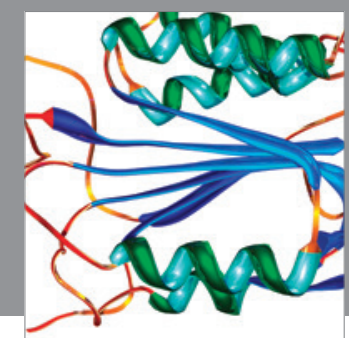

Disease Markers
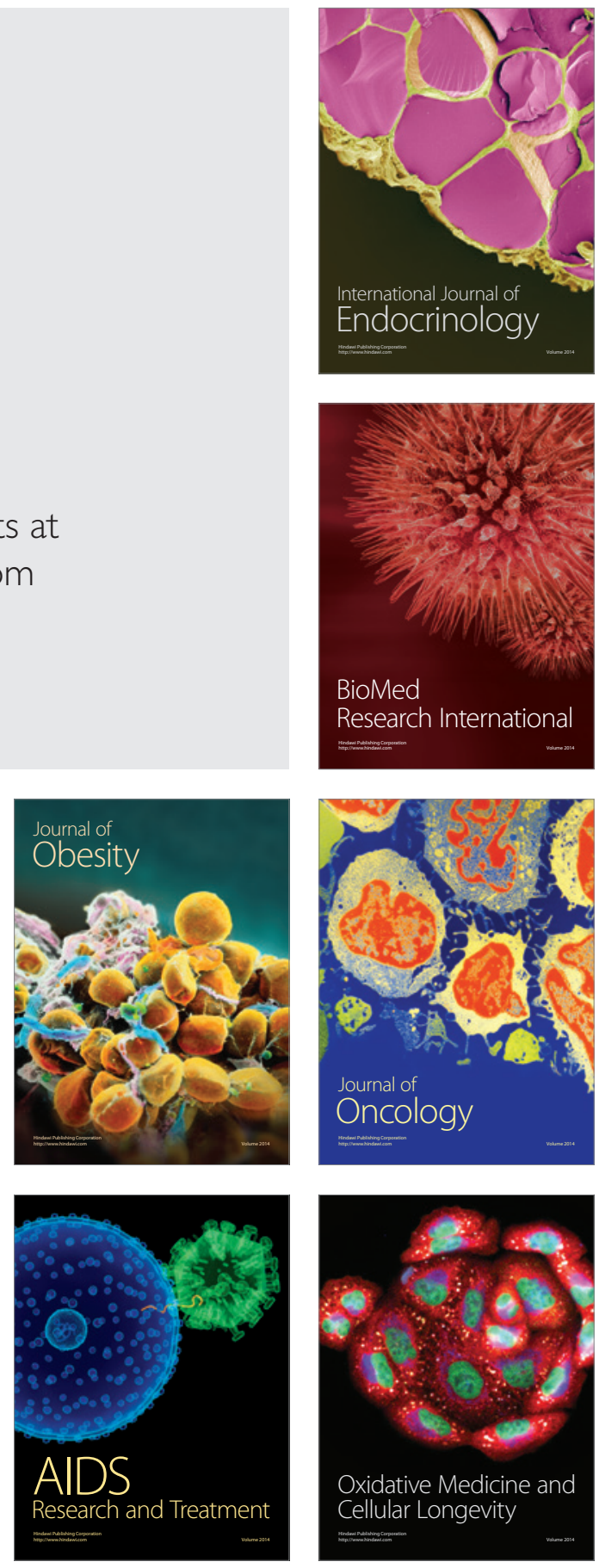